\title{
A importância do meio físico para o manejo sustentável de plantio de eucalipto em áreas de terrenos acidentados - A fazenda Santa Edwirges, Vale do Paraíba, Sudeste do Brasil
}

\author{
Silvio Jorge C. Simões ${ }^{1}$ \\ George de Paula Bernardes ${ }^{1}$ \\ Isabel Cristina de Barros Trannin ${ }^{1}$ \\ Paulo Valladares Soares ${ }^{2}$ \\ Sueli Yoshinaga Pereira ${ }^{2}$ \\ Maria José Brito Zakia ${ }^{3}$ \\ Juliano Ferreira Dias ${ }^{4}$
}

\begin{abstract}
${ }^{1}$ Universidade Estadual Paulista (UNESP), Faculdade de Engenharia de Guaratinguetá, Departamento de Engenharia Civil E-mail: simoes@feg.unesp.br, gpb@feg.unesp.br, isatrannin@uol.com.br

${ }^{2}$ Universidade Estadual de Campinas (Unicamp), Instituto de Geociências. E-mail: sueliyos@ige.unicamp.br

${ }^{3}$ Consultora Ambiental E-mail: <zezezakia@uol.com.br>,

${ }^{4}$ Fibria E-mail: juliano.dias@fibria.com.br
\end{abstract}

\section{Importance of landscape physical elements for evaluating high mountain eucalyptus forest management, Santa Edwirges Farm, Paraiba Valley, Southeast Brazil}

\begin{abstract}
This study intends to evaluate the effects of landscape physical elements (rocks, relief and soils) associated with silviculture activities. The study was carried out on a small farm (Fazenda Santa Edwirges) covered by Eucalyptus forested situated in the Paraiba do Sul Basin, Southeast Brazil. The methodology consisted of detailed geological and geomorfological studies at 1:10000 scale, and laboratory analysis of soil physical properties. In the Northeast region, the association between granite rocks and escarpments has produced intense erosional processes, sometimes related to landslides features. In the Southeast region, on the contrary, the association between biotite-rich gneiss rocks and mountain relief do not present high vulnerabity to linear erosion and landslides features. The results have showed the importance of considering the interactions among landscape physical elements to the different silviculture activities especially in regions with high geological and geomorfological diversity.
\end{abstract}

Key Words: physical elements; geotechnical analysis; eucalyptus forest management

\section{Introdução}

A atividade de silvicultura deve se basear em um processo dinâmico na busca da melhor sustentabilidade das florestas plantadas. Para isto não se deve apenas seguir os procedimentos das normas ambientais, mas buscar considerar, entre outros fatores, as potencialidades e vulnerabilidades do meio físico de cada região.

A avaliação dos atributos do meio físico é um fator determinante a se considerar em uma área com atividade silvicultural com vistas a definir a proporção da área de plantio e a prever/mitigar os prováveis processos do meio físico sobre a paisagem. Esta importância tende a aumentar na medida em que as áreas de florestas plantadas se situam em áreas com grande diversidade de rochas e relevos recortando diferentes unidades geológicas e geomorfológicas. Dependendo das especificidades do meio físico, uma determinada área pode ser propícia ao aparecimento e desenvolvimento de processos potencializando fenômenos como a erosão acelerada, os movimentos de massa e o assoreamento dos corpos de água. 
Em que pese à importância de se avaliar o meio físico na busca da sustentabilidade ambiental das florestas plantadas, o tema é praticamente inexistente tanto na literatura nacional quanto internacional. A maior parte dos trabalhos discute os efeitos dos processos hidrológicos e características específicas dos solos (LIMA, 1996; LIMA \& ZAKIA, 2006), a produção de sedimentos (ZHOU et al., 2002) e os efeitos da conservação da vida selvagem (LINDENMAYER, 1995; MCCARTHY \& LINDENMAYER, 1998). De uma maneira geral, estes trabalhos não consideram uma abordagem integrada dos elementos que integram o meio físico.

Com base nestas considerações, o objetivo deste trabalho é apresentar e discutir, preliminarmente, como o entendimento da dinâmica do meio físico pode contribuir para a preservação dos recursos naturais (água - solo - fauna - flora) em uma área com plantio de eucalipto.

Para isto se busca descrever e analisar os elementos e processos relacionados aos atributos geológicos, geomorfológicos e geotécnicos no sentido de avaliar a fragilidade potencial de uma região montanhosa situada no Alto e Médio Vale do Paraíba do Sul, Estado de São Paulo. A área de estudo é a fazenda Santa Edwirges, de propriedade da empresa Fibria a qual se encontra nos domínios de morros e serras ligados aos relevos da Serra do Mar.

\section{Localização da Área de Estudo}

A área da fazenda Santa Edwirges (figura 1) situa-se próximo ao divisor de águas da Serra do Quebra Cangalha, a qual se constitui uma elevação da Serra do Mar no município de Lorena, Estado de São Paulo. A fazenda tem uma área de $22 \mathrm{~km}^{2}$ e nela se encontra parte das nascentes do ribeirão Taboão. Este curso de água é um dos afluentes da margem direita do rio Paraíba do Sul, o qual nasce na Serra do Quebra-Cangalha (domínio da Serra da Mantiqueira), numa altitude de aproximadamente 1.240 metros até desaguar em meio à planície aluvionar do rio Paraíba do Sul a 550 metros de altitude, na área urbana do município de Lorena.

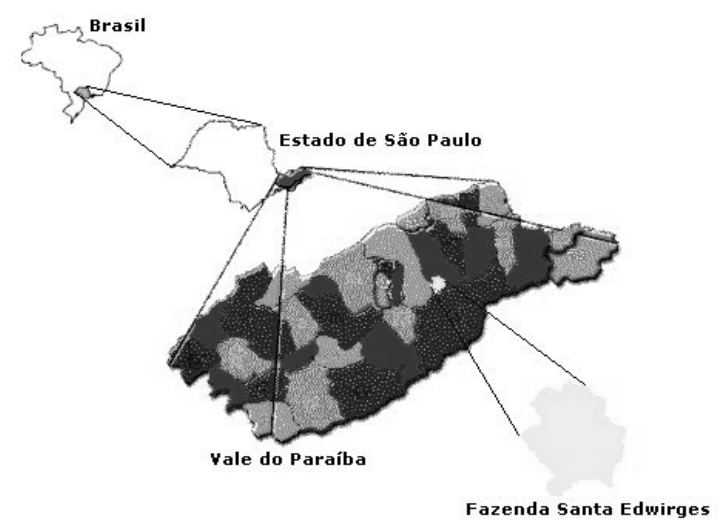

Figura 1 - Localização da área de estudo

A tabela 1 apresenta as proporções de uso da terra na Fazenda Santa Edwirges na qual se pode observar que a área de plantio corresponde a 52,8\% e as áreas de preservação permanente e reserva legal corresponde a $43,8 \%$ da área total da fazenda. 
Tabela 1 - Uso da terra na Fazenda Santa Edwirges, Lorena/SP

\begin{tabular}{ccc}
\hline Uso do solo & Área (ha) & Participação (\%) \\
\hline Plantio de eucalipto & 680,2 & 52,8 \\
Área de Preservação Permanente & 546,7 & 43,8 \\
e Reserva Legal & & \\
Estradas e aceiros & 28,8 & 2,2 \\
Rede elétrica, construções, & 15,0 & 1,2 \\
represa e bambu & & 100,0 \\
Total & 1287,7 & 100 \\
\hline
\end{tabular}

\section{Metodologia}

Os diferentes atributos do meio físico foram representados cartograficamente em uma mesma escala (1:10.000) a qual é compatível com a dimensão da área estudada $\left(22 \mathrm{~km}^{2}\right)$. Os mapas foram digitalizados e analisados em um ambiente SIG (Sistemas de Informação Geográfica) utilizando-se o programa Arc-GIS ${ }^{\circledR}$ versão 9.0 disponível no Laboratório de Análise Geo-Espacial (LAGE) da FEG-UNESP.

Para a elaboração do mapa geológico se considerou os aspectos litológicos (tipos de rochas) e estruturais (falhas e fraturas) sendo produzido a partir da análise de fotografias aéreas de 1973 (1:25.000), de imagens Landsat - TM e dos mapas regionais existentes. Para o levantamento das características do relevo foram avaliados parâmetros morfométricos. O mapa hipsométrico foi produzido a partir da elaboração de um Modelo Digital de Terreno - MDT (Figura 2). O mapa de declividade foi obtido a partir do MDT tendo sido definidas seis classes com base na variação de relevo, na legislação ambiental e nas diversas fases de operação que envolvem as atividades de silvicultura (Tabela 3).

Tabela 2 - Classes de declividade

\begin{tabular}{cc}
\hline Classes & Declividade $(\%)$ \\
\hline 1 & $0-3$ \\
2 & $3-15$ \\
3 & $15-25$ \\
4 & $25-42$ \\
5 & $42-100$ \\
6 & $>100$ \\
\hline
\end{tabular}

A classe entre 0 e $3 \%$ corresponde as áreas próximas ao topo dos morros e colinas e as áreas de planície aluvionar dos rios, enquanto a classe entre 5 e $15 \%$ corresponde às vertentes dos relevos mais suaves. O valor de $25 \%$ corresponde ao limite superior para operar tratores agrícolas; o valor de $42 \%$ corresponde ao limite máximo para operar a máquina colheitadeira de eucalipto; o valor de $100 \%$ corresponde ao limite mínimo para área de proteção permanente conforme o Código Florestal Lei no 4.771, de 15/09/1965.

Para a realização dos ensaios geotécnicos foram coletadas amostras de solo representativas das principais unidades geológicas/geomorfológicas identificadas na área de estudo. Os ensaios em laboratórios envolveram tanto amostras deformadas quanto indeformadas. Para as amostras deformadas foram realizados ensaios para determinação da curva granulométrica (com e sem defloculante), teor de umidade natural e higroscópica, massa específica dos grãos, limites de liquidez e plasticidade. Para as amostras "indeformadas" foram obtidos os seguintes parâmetros: massa específica natural, massa específica seca, índice de vazios, e porosidade. As curvas características (curva que relaciona a variação da umidade do solo com a sucção) e a resistência à 
tração das amostras de solo foram obtidas para as principais unidades geológicas/ geomorfológicas da área de estudo.

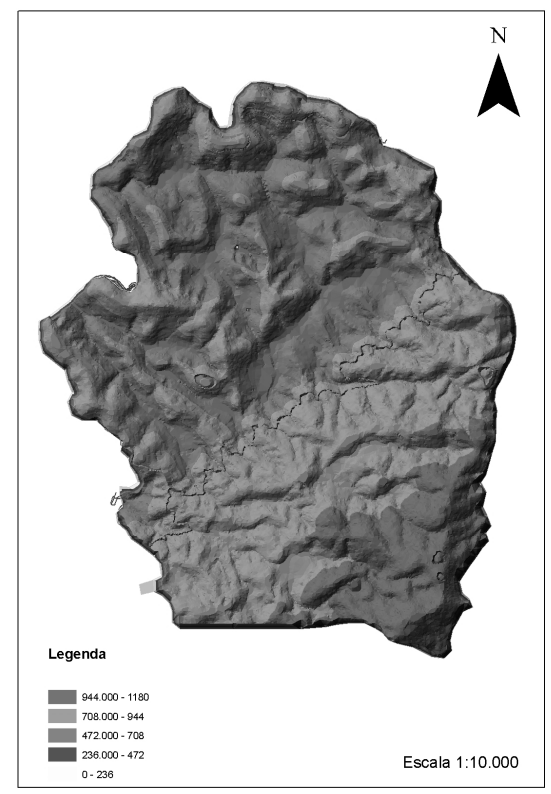

Figura 2 - Modelo Digital de Terreno da área de estudo

Na campanha de ensaios de campo foram realizados ensaios para determinação da taxa de infiltração superficial (Infiltrômetro Cilíndrico) e ensaios de condutividade hidráulica saturada considerando as profundidades de 20,50 e 100 centímetros através do Permeâmetro de Guelph. Para se avaliar a influência das mudanças sazonais nas propriedades dos solos, foram realizados ensaios os quais relacionam a capacidade de desagregação do solo como função da variação da umidade e sua respectiva resistência à tração.

\section{Resultados}

\subsection{Caracterização geológica e formações superficiais}

A fazenda Santa Edwirges encontra-se totalmente inserida em um contexto geológico formado por rochas cristalinas de idade precambriana ( $>500$ milhões de anos). O mapa da figura 3 apresenta as diferentes unidades geológicas encontradas na região: a) rochas metamórficas (xistos, gnaisses e migmatitos) do Complexo Embu (HASUI \& SADOWSKI, 1976; CARNEIRO et al., 1978; LANDIM, 1984); b) rochas ígneas (de composição predominantemente granítica) do Complexo Quebra-Cangalha (LANDIM, 1984); c) as faixas de alta deformação (zonas milonitizadas); d) os terraços fluviais compostos de silte e argila e e), os sedimentos inconsolidados localizados no leito dos cursos de água.

Pela figura 3 pode-se perceber que a grande maioria da área é constituída pelo Complexo $E m b u$, o qual corresponde a $60 \%$ da área de estudo. Esta unidade é constituída por rochas metamórficas (gnaisses) que possuem na sua composição minerais mais facilmente alteráveis como micas e feldspatos. Desta maneira, o solo de alteração proveniente destas rochas é normalmente fino onde predominam minerais argilosos favorecendo o desenvolvimento de solos mais impermeáveis e mais homogêneos. Os solos são normalmente espessos e possuem 
coloração avermelhada devido à presença de minerais ricos em ferro como a biotita. A homogeneidade e a composição fina destes solos são fatores que dificultam o desenvolvimento de processos erosivos acelerados como as ravinas.

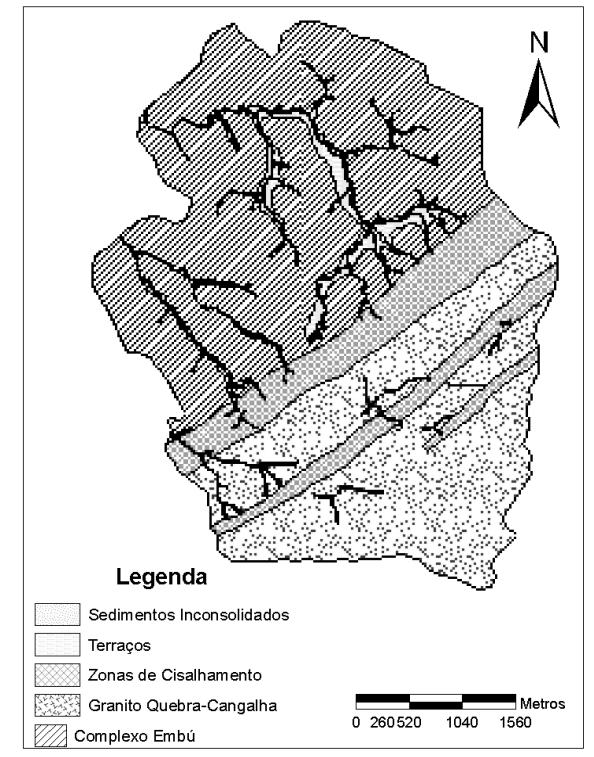

Figura 3 - Mapa geológico simplificado da área de estudo

A unidade Granitóide Quebra-Cangalha corresponde a 35\% do mapa geológico da área da Fazenda santa Edwirges sendo constituído predominantemente por granitos leucocráticos (de tonalidades claras). As rochas desta unidade possuem minerais mais resistentes à alteração como o quartzo e o feldspato potássico. Entretanto, em decorrência da presença destes minerais, os solos são predominantemente de coloração esbranquiçada, de constituição areno-argilosa e com a presença significativa de frações minerais mais grosseiras (saibros). A textura grossa destes solos e a ausência de uma cobertura vegetal fornecem as condições favoráveis para a ocorrência de processos erosivos acelerados como sulcos e ravinas.

As zonas milonitizadas (ou zonas de cisalhamento) correspondem à cerca de $10 \%$ da área total estudada. Estas regiões correspondem a áreas que foram submetidas a intensas tensões tectônicas em condições dúcteis, ou seja, a profundidades maiores que $10 \mathrm{~km}$ (RAMSAY, 1980). Por esta razão, apresentam uma foliação bastante desenvolvida e a presença de minerais finos com estrutura em camadas como mica e clorita em decorrência de processos de retrometamorfismo. A alteração destas rochas produz solos com elevada proporção de argila e não são suscetíveis ao aparecimento de processos erosivos lineares.

A unidade Terraço Fluvial e a unidade Sedimentos Inconsolidados correspondem a 5\% do mapa geológico e representam a planície fluvial do ribeirão Taboão e seus principais afluentes. Nesta área são identificados paleo-terraços com sedimentos de composição pelítica (silte e argila) e, secundariamente, areia e seixos angulosos de quartzo e feldspato. Também se observam sedimentos inconsolidados de cor preta indicando a presença de solos com grande quantidade de matéria orgânica. No aspecto geotécnico constituem-se solos de baixa resistência, saturados em água e propícios à inundação. 


\subsection{Caracterização geomorfológica}

Ainda que se constitua de uma área relativamente pequena, a fazenda Santa Edwirges possui uma significativa variação no relevo. Isto se deve, em grande parte, a diversidade do substrato geológico descrita anteriormente. Regionalmente, a área está inserida na unidade geomorfológica do Planalto do Médio Vale do Paraíba (PONÇANO et al., 1981). Na escala de trabalho adotada $(1: 10.000)$ três unidades geomorfológicas distintas foram identificadas com base em elementos morfométricos (hipsomteria e declividade):

a) Escarpas Degradadas - ocorrem no terço superior da área estudada apresentando declividades dominantes superiores a $30 \%$, topos normalmente estreitos e alongados e afloramentos esporádicos de blocos de rochas. O substrato destas rochas é formado principalmente pelas rochas graníticas da Unidade Quebra-Cangalha.

b) Morros e Morrotes - ocupa a porção centro-norte da área de estudo apresentando declividades dominantes entre 20 e $30 \%$ e topos com formas arredondadas. Neste relevo se observa uma menor intensidade dos processos de dissecação que no relevo de Escarpas Degradadas. Geologicamente, correspondem a rochas gnáissicas e migmatíticas. Os solos associados são normalmente argilosos, espessos e de coloração avermelhada. A atividade erosiva é predominantemente laminar ainda que feições erosivas lineares ocorram de maneira localizada.

c) Colinas Alveolares - ocupa uma faixa de direção sudoeste/nordeste na parte central da bacia. Representam a transição entre os relevos de escarpas e os relevos de morros e morrotes. Correspondem as áreas de declividade baixa (inferiores a 15\%) e as áreas de relevo plano (planícies aluvionares). Em alguns lugares foi possível identificar a deposição de sedimentos recentes (Terciários/Quaternários) os quais corresponde a unidade geológica Terraço Fluvial. Estes relevos possuem grande influência na dinâmica hidrológica da sub-bacia por se constituírem em um local apropriado para a formação de bacias de retenção.

\subsection{Caracterização geotécnica}

As características geológicas e geomorfológicas da região, conforme descritas acima, criaram ambiente propício para a formaçãoe evolução de solo com características bem distintas. Para ilustrar como as propriedades dos solos são utilizadas para caracterização de indicadores de controle e monitoramento, a figura 4 apresenta as curvas granulométricas obtidas com e sem defloculante sendo a figura 5A referente a uma amostra de solo residual jovem da região de granito e a figura 5B, referente a uma amostra de solo residual maduro da região de gnaisse.
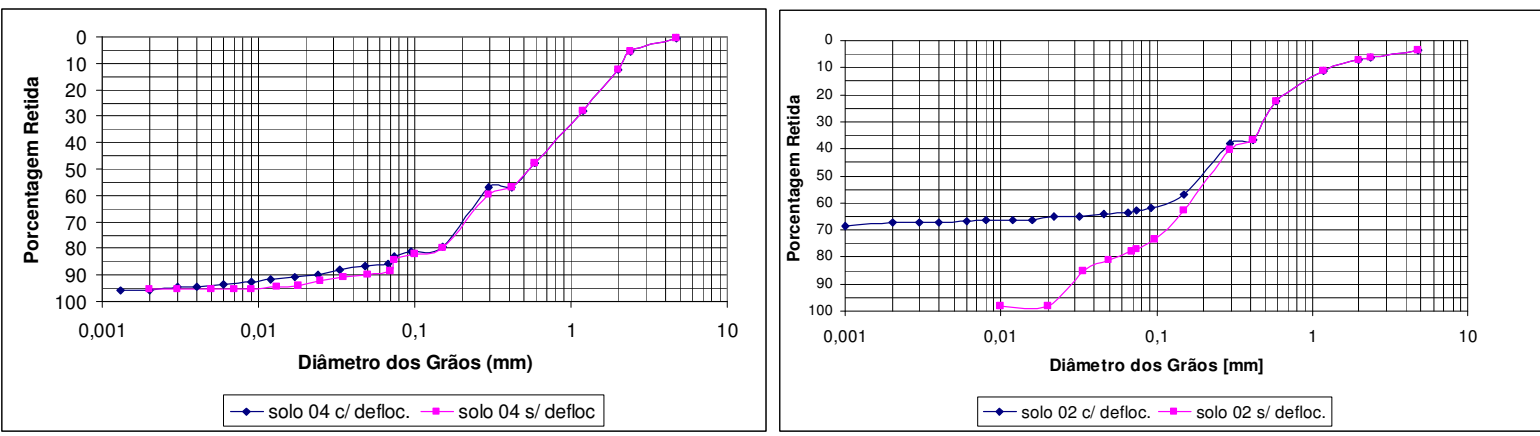

Figura 4 - Curvas granulométricas com e sem defloculante (A) solo residual jovem e (B) solo residual maduro 
A comparação entre curvas granulométricas - obtidas com e sem defloculante - fornecem um indicativo das características de erodibilidade do solo. Para solos com baixos teores de minerais argílicos (figura 4A) em rochas graníticas, a interação entre partículas é fraca, conseqüentemente, não existem diferenças significativas nas curvas obtidas com e sem defloculante. Isso quer dizer que este solo desagrega com facilidade com a ação das chuvas e do escoamento superficial. Por outro lado, para solos com teor de mineral argílico alto (figura 4B), em rocha gnáissica, existe uma grande diferença entre as curvas porque a interação entre partículas sem o defloculante é grande formando grumos que apresentam maior resistência ao arranque e arrasto. O estudo detalhado da erodibilidade dos solos da região é apresentado por Santos et al. (2006).

O efeito das mudanças sazonais, ou melhor, da variação da sucção nas características de erodibilidade dos solos da região pode ser avaliada pela figura 5. A figura 5A apresenta a curva característica obtida e a figura 5B apresenta a variação da resistência à tração em função da variação da umidade volumétrica.
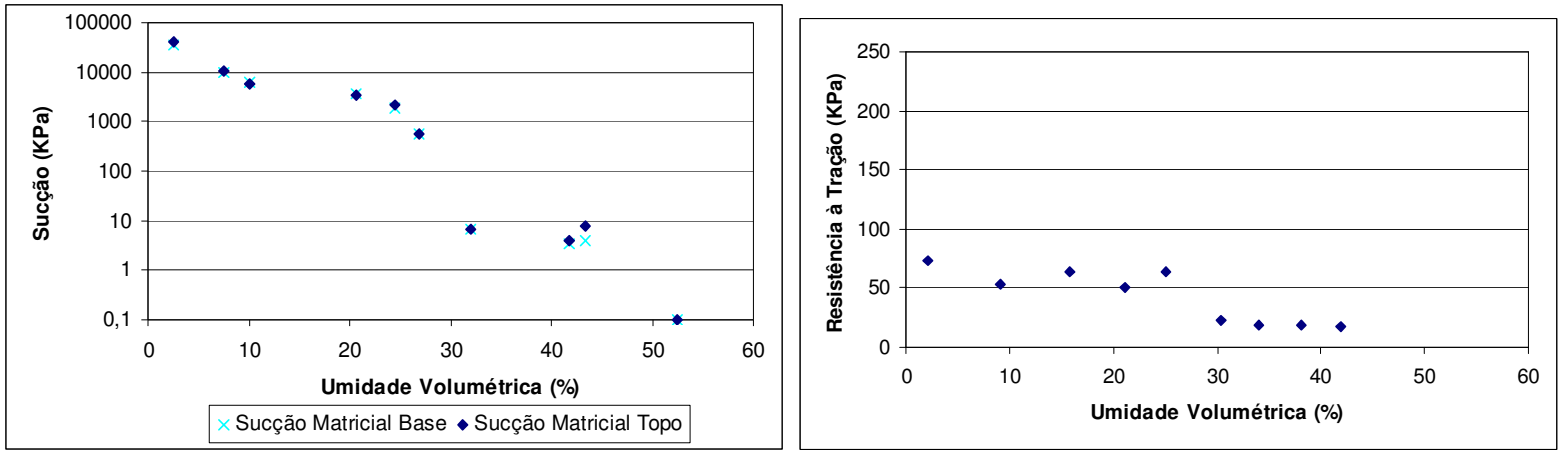

Figura 5 - (A) Curva Característica (Umidade Volumétrica x Sucção); (B) Representação da resistência à tração.

Os dois gráficos (figuras 5A e 5B) indicam que existe uma faixa de variação da umidade volumétrica entre 5 e $25 \%$ onde a resistência à tração fica praticamente constante na faixa de 60 $\mathrm{kPa}$. Para umidades acima de 25\%, ocorre uma queda brusca da sucção, de 1000 para menos de $10 \mathrm{kPa}$, com conseqüente redução da resistência à tração (+/- $20 \mathrm{kPa})$. A relação entre as condições iniciais do solo e a intensidade e duração da chuva vão determinar o risco de ocorrer erosão neste solo. Para a região em estudo, foram desenvolvidos mapas de índices de erosão (SANTOS et al., 2007) aos quais levaram em consideração as inter-relações existentes entre a declividade do terreno, o uso do solo, a erosividade da chuva $\left(\mathrm{EI}_{30}\right)$ e a erodibilidade do solo em função do tipo de ensaio realizado.

\section{Discussão}

As constantes alterações impostas ao meio físico geram modificações nas relações entre os sistemas bióticos e abióticos produzindo consequiências profundas sobre a paisagem através dos processos oriundos da dinâmica do meio físico intensificando fenômenos como erosão acelerada, assoreamento, inundação e variação no nível freático.

Nas condições climáticas existentes no sudeste brasileiro (tropical úmido em parte do ano), os processos modeladores do relevo são, em grande parte, resultantes de ação dos regimes hidrológicos, que possuem grande influência sobre o substrato geológico e os processos geomorfológicos. A ruptura de equilíbrio do meio físico é quase sempre evidenciada na época das 
chuvas. Em diferentes escalas da paisagem, ocorre uma forte correlação entre os processos geomorfológicos, a distribuição do fluxo de água (superficial e subsuperficial) e os sedimentos em suspensão que convergem para um ponto de saída comum normalmente o exutório de uma bacia hidrográfica.

No caso da área de estudo, a região que apresenta a associação entre rochas graníticas e relevos montanhosos de escarpas (figuras 3 e 4) gera condições favoráveis para a evolução dos processos erosivos lineares particularmente quando associados com a construção de estradas nãopavimentadas. Os solos provenientes de rochas graníticas observados são formados normalmente por solos residuais jovens (horizontes $\mathrm{C}$ ) com uma elevada quantidade de minerais primários e baixas interações entre partículas (figura 5a).

Neste sentido, o planejamento prévio do desenho de estradas e de outras obras de engenharia em áreas de silvicultura deve levar em consideração as características dos solos, das rochas e dos tipos de relevo no intuito de aprimorar o seu traçado e diminuir os custos de manutenção. Isto é particularmente uma necessidade em áreas de relevos montanhosos no qual a sua evolução se faz geralmente a partir de processos de ravinamento (ou voçorocamento) e de diferentes formas de escorregamentos.

\section{Conclusão}

A análise do meio físico visando a otimização e a racionalização do uso e ocupação do solo em áreas de florestas plantadas se constituem instrumentos fundamentais para a sua gestão e manejo, particularmente em áreas de grande complexidade geológica-geomorfológica. A área da fazenda Santa Edwirges se constitui um bom exemplo desta situação. A combinação entre rochas graníticas e relevos de escarpas, situadas na sua porção sul, mostraram-se particularmente propícias para a evolução e intensificação dos processos erosivos e feições de escorregamento. A análise dos ensaios geotécnicos dos solos associados a este ambiente constatou que estes solos desagregam com facilidade. Ao contrário, as rochas de composição biotita-gnaisse associadas ao relevo de morros e morrotes apresentaram baixa intensidade dos processos os quais pode ser explicada pelo maior resistência ao arranque e arrasto dos solos oriundos destas rochas o qual foi bem evidenciado nos ensaios geotécnicos realizados.

Esta análise, ainda que preliminar, mostrou a importância de se considerar o sistema rocha relevo - solo no sentido de caracterizar as áreas onde o plantio de silvicultura poderia estar associado com maior fragilidade e maior aceleração dos processos do meio físico (por ex., erosão linear e escorregamentos). Além disto, esta análise sistemática permite maior racionalidade nas diferentes formas de intervenções em diferentes escalas (pontuais e regionais) da atividade de silvicultura. Isto possibilita que, no caso de estradas vicinais, se possam mitigar os custos de manutenção e, sobretudo, os custos ambientais provenientes de traçados que apenas levem em consideração os aspectos de implantação e de colheita.

\section{Referências bibliográficas}

BURROUGH, P.A.; MCDONELL, R.A. Principles of Geographical Information Systems. Oxford: Oxford Press. 1998. 333p.

CARNEIRO, C.D.R.; HASUI, Y.; GIANCURSI, F. D. Estruturas da Bacia do Taubaté na região de São José dos Campos. In: CONGRESSO BRASILEIRO DE GEOLOGIA, 29, Ouro Preto. 1978. Anais...Belo Horizonte: SBG, v. 4, 1978. p. 247-256. 
CEIVAP (Comitê para a Integração da Bacia Hidrográfica do Rio Paraíba do Sul) Projeto Qualidade das Águas e Controle da Poluição Hídrica (PQA). Relatório Executivo. São Paulo: CEIVAP, 2000. 122p.

DEAN, W. - With broadax and fireland: the destruction of the Brazilian forests. San Francisco: University of Califórnia Press, 1995. 402p.

FORMAN, R.T. Land mosaic. The ecology of landscape and regions. Nova York: Cambridge University Press, 1995. 632p.

FORMAN, R.T.; GODRON, M. Landscape ecology. Nova York: John Wiley, 1986. 619p.

HASUI, Y.; SADOWSKI, G. Evolução geológica do precambriano na região sudeste de São Paulo. Revista Brasileira de Geociências, São Paulo, v. 6, p. 187-200, 1976.

LANDIM, P.M.B. (coord.) Mapa Geológico de Estado de São Paulo. Escala 1:50.000, São Paulo: IGCE/UNESP, 1984.

LIMA, W.P. Impacto ambiental do eucalipto. São Paulo: EDUSP, 1996. 301p.

LIMA, W.P.; ZAKIA, M.J.B. As florestas plantadas e a água. Rio Claro: Editora Rima, 2006. 218p.

PONÇANO, W.L.; CARNEIRO, C.D.R.; BISTRICHI, C.A.; ALMEIRA, F.F.M.; PRANDINI, F.L. Mapa Geomorfológico do Estado de São Paulo. Escala 1:500.000, São Paulo: IPT, 1981.

RAMSAY, J. Shear zones geometry: a review. Journal of Structural Geology, Mainz, v. 2, p 8399, 1980.

SANTOS, C.M.Z.; BERNARDES, G.P.; SIMÕES, S.J.C. Estudo da erodibilidade dos solos da bacia hidrográfica do ribeirão Taboão, Lorena,SP. In: XIII Congresso Brasileiro de Mecânica dos Solos e Engenharia Geotécnica, Curitiba. 2006. Anais ... Curitiba, ABMS, vol. 3. 2006. p. 1773-1778.

SANTOS, C.M.Z.; BERNARDES, G.P.; SIMÕES, S.J.C.; AUTOMARE, G.B.B. Proposta metodológica para a caracterização de áreas com potencial de erosão. In: III Simpósio Sobre Solos Tropicais e Processos Erosivos no Centro-Oeste, Cuiabá. 2007. Anais,,, Cuiabá: ABMS, 2007. CD-Rom.

VIANA, L.G.G.; SATO, A.M.; FERNANDES, M.C.; COELHO NETO, A.L. Fronteiras de expansão dos plantios de eucaliptos nos geossistemas do Médio Vale do Paraíba do Sul (SP/RJ). In: I Seminário de Recursos Hídricos da Bacia Hidrográfica do Paraíba do Sul: o Eucalipto e o Ciclo Hidrológico, Taubaté, 2007. Anais... Taubaté, IPABHi, p. 367-369.

ZHOU, G.; WEI, X.; YAN, J. Impacts of eucaliptus (Eucaliptus exserta) plantation on sediment yield in Guangdong Province, Southern China - a kinetic energy approach. Catena, Cambridge, v. 49, p. 231-251, 2002. 